BMJ Open Sport \& Exercise Medicine

\title{
Clinical reasoning framework for thoracic spine exercise prescription in sport: a systematic review and narrative synthesis
}

\author{
Nicola R Heneghan (D) , ${ }^{1}$ Svein M Lokhaug, ${ }^{1,2}$ Isaak Tyros, ${ }^{3}$ Sigurd Longvastøl, ${ }^{4}$ \\ Alison Rushton (1) ${ }^{1}$
}

To cite: Heneghan NR, Lokhaug SM, Tyros I, et al. Clinical reasoning framework for thoracic spine exercise prescription in sport: a systematic review and narrative synthesis. BMJ Open Sport \& Exercise Medicine 2020;6:e00713. doi:10.1136/ bmjsem-2019-000713

- Additional material is published online only. To view please visit the journal online (http://dx.doi.org/10.1136/ bmjsem-2019-000713).

Accepted 23 February 2020

Check for updates

\section{(C) Author(s) (or their} employer(s)) 2020. Re-use permitted under CC BY-NC. No commercial re-use. See rights and permissions. Published by BMJ.

${ }^{1}$ Centre of Precision Rehabiliation for Spinal Pain (CPR Spine), School of Sport, Exercise \& Rehabilitation Sciences, University of Birmingham, Birmingham, UK ${ }^{2}$ Helsefag, Norwegian Institute of Sport Medicine, Oslo, Norway

${ }^{3}$ Edgbaston Physiotherapy Clinic, Birmingham, UK

${ }^{4}$ Molde Performance Center AS, Molde, Norway

\section{Correspondence to} Nicola R Heneghan; n.heneghan@bham.ac.uk

\section{ABSTRACT}

Background The thoracic spine is critical for athletic kinetic chain functioning yet widely overlooked in terms of specific evidenced-based exercise prescription. Thoracic mobility, motor control and strength are required to optimise performance in sport and minimise excessive load/stress on other components of the kinetic chain. Objective To identify and evaluate mobility, motor control, work capacity and strength thoracic exercises for use in athletes.

Design Systematic review involving expert reviewers at key stages: searches and screening $(n=1)$, eligibility, evaluation, data extraction and evaluation $(n=3)$. Key databases and social media sources were searched to 16 August 2019. Eligible exercises were thoracic exercises to promote mobility, motor control, work capacity and strength. A narrative synthesis enabled an outcomebased classification of exercises, with level of evidence of individual sources informing overall level of evidence for each outcome (0xford Centre for Evidence-based Medicine).

Results From 2348 sources (social media, database searches and other sources), 38 exercises were included. Sources included images, video clips and written descriptions of exercises. Exercises targeting all planes of motion were evaluated and classified according to outcome. Exercises comprised functional and nonfunctional exercises for mobility ( $n=9)$, work capacity $(n=15)$, motor control $(n=7)$ and strength $(n=7)$. Overall level of evidence for each outcome was level 5 .

Conclusion This synthesis and evaluation of exercises has captured the scope of thoracic exercises used in 'practice'. Evaluation against an expert-derived outcomebased classification provides practitioners with a framework to facilitate exercise prescription. Evaluation of validity and effectiveness of exercises on outcomes is now required.

\section{INTRODUCTION}

The ability of the musculoskeletal system to generate, mediate and tolerate forces underpins sporting performance. Musculoskeletal adaptations characterise the observed sportspecific bioplasticity and should inform

\section{Summary box}

What is already known?

- The thoracic spine is a critical component of athletic functional kinetic chains yet little is known about exercise prescription in this relatively stiff spinal region

- Sources detailing thoracic spine exercises are extensive on social media but have not been formally incorporated into evidence based practice.

- There are no trials investigating the effectiveness of thoracic spine exercises in prevention or rehabilitation of sports injuries

\section{What are the new findings?}

- A comprehensive evidence synthesis details thoracic spine exercises drawn from databases and social media sources to support evidence based practice.

- Thoracic spine exercises classified according to aim, mobility, motor control, work capacity and strength are presented within a clinical reasoning framework to support personalised rehabilitation and injury prevention.

- This synthesis of thoracic spine exercise prescription can be used to inform further targeted research of effectiveness according to desired outcome.

exercise prescription in training and rehabilitation. Given the complexity of the musculoskeletal system, 'classification' has long been used to facilitate the study of discrete components with common attributes. Guiding lines of focused research, a plethora of 'classification systems' now exist in skeletal muscle exercise literature related to; structure (architecture), metabolic characteristics (fibre type), location (deep or superficial), exercise type (eccentric or concentric), etc. These mutually exclusive classification systems do however create confusion for practitioners to inform their evidence-based exercise prescription in practice as a focus on functional performance is required. To assist decision-making in spinal exercise prescription in sport, Spencer et al conceived and 
developed an evidence informed outcome focused spinal exercise classification. Multidisciplinary sport experts agreed four spinal ability dimensions of mobility, motor control, work capacity and strength; with subcategories to delineate static and dynamic spinal displacement. They subsequently classified exercises according to key parameters of function/non-functional, segmental, pillar or whole-body, dissociation or stabilisation, etc. The framework $^{1}$ provides the basis to develop and evaluate region-specific exercises to support precision of exercise prescription in sport.

Coined the 'Cinderella' region, ${ }^{2}$ the thoracic spine is pivotal to sporting performance. Biomechanically, the thoracic spine contributes to an estimated $55 \%$ of the total force and kinetic energy generated during a throw, ${ }^{3}$ around $80 \%$ of the total available range of trunk axial rotation, ${ }^{4}$ and is kinematically linked to the upper $\operatorname{limb}^{5-7}$ and other spinal regions. ${ }^{8}$ Although widely overlooked, evidence does support a focus on this spinal region, with three times higher elbow or shoulder injury prevalence in softball players with low trunk rotation flexibility ${ }^{9}$ and altered trunk rotation (timing of movement initiation and peak force) related to increased shoulder external rotation $(>7$ degrees, $\mathrm{p}<0.016)$ in baseball pitchers. ${ }^{10}$ The concept of "regional interdependence' has been adopted to describe how symptoms in one region may be secondary to asymptomatic impairment or 'dysfunction' in another; ${ }^{11}$ although originated from the observation that musculoskeletal regions are biomechanically and neurophysiologically inextricably linked with muscles synergies working across joints to execute a movement. ${ }^{11}$

Research investigating thoracic spine exercise is lacking and with just a few reliability studies examining thoracic axial rotation in postures or positions other than sitting. ${ }^{12-14}$ Sitting lacks specificity to the thoracic region being a composite of movement occurring in the thoracic and lumbar spines. Favourable outcomes have been reported using passive interventions targeting the thoracic spine in neck and shoulder complaints, ${ }^{15-17}$ and to the authors' knowledge just one study has investigated an active intervention, where a shoulder injury prevention programme that included thoracic mobility exercises resulted in $28 \%$ and $22 \%$ lower risk of shoulder and substantial shoulder problems, respectively. ${ }^{18}$

From a scoping search of the evidence and available resources, there is also a gulf between those thoracic exercises being taught, promoted and advocated on social media platforms and those which have been investigated empirically to inform evidence-based thoracic spine exercise prescription. For practitioners to have confidence in evidenced-based exercise prescription in the thoracic spine, it is vital that we are precise with respect to a focus on outcomes and to establish the effectiveness of a range of exercises. The aim, therefore, of this study was to review exercise prescription in the thoracic spine using the evidence-based spinal exercise classification. ${ }^{1}$

\section{Objectives}

- To identify prescribed thoracic spine exercises in sport.

- To evaluate exercises according to aim, mobility, motor control, work capacity and strength.

- To provide a framework to support precision in thoracic spine exercise prescription.

\section{METHODS}

\section{Design}

A systematic review and narrative synthesis was conducted in accordance with a predesigned unpublished protocol informed by the Centre for Reviews and Dissemination (CRD) guidance $\cdot{ }^{19}$ From scoping searches, it was evident that inclusion of non-empirical sources including social media was required to capture the scope of thoracic spine exercises being promoted by practitioners through different media. ${ }^{20}$ The search strategy was informed by subject (NRH, SML, IT and AR) and methodological expertise (NRH, IT and AR), and is reported in line with a modified Preferred Reporting Items for Systematic Reviews and Meta-Analyses statement for transparency. ${ }^{21}$

\section{Eligibility criteria}

Eligibility criteria were derived from the search concept tool SPIDER: ${ }^{22}$

- Sample: athletic population (aged 18-40) participating in competitive sport and/or physical exercise aimed at improving athletic ability.

- Phenomenon of interest: exercises and descriptions of exercises targeting the thoracic spine. Exercises focused to breathing or principally investigating scapular motor control were excluded; where the latter of this has been reported elsewhere. ${ }^{23}$

- Design: any source (database, video or image).

- Evaluation: Exercises were classified according to its main aim:

- Mobility defined as 'develop, maintain, or restore global spinal range of movement through a specific range of motion'. (p. 618) ${ }^{1}$

- Motor control defined as 'the maintenance of spinal integrity during skilled movement'. (p. 618) ${ }^{1}$

- Work capacity defined as 'the ability to produce or tolerate variable intensities and duration of work' ( $p$. $618)^{1}$; synonymous with local muscular endurance. (p. 618) ${ }^{1}$

- Strength defined as the ability to produce force and maximal strength is the largest force the musculature can produce'. (p. 619) ${ }^{1}$

\section{Information sources}

Following a number of scoping searches, information sources included databases (Medline, Google Scholar, Pedro, SportDiscus, Pubmed and Index to Chiropractic literature), key journals (British Journal of Sports Medicine, Medicine and Science in Sports and Exercise, American Journal of Sports Science and Medicine, Journal of Strength and Conditioning Research and Sports Medicine) and social media 
sources (Facebook, Vimeo, Twitter, YouTube and Instagram). Citations were checked of included articles.

\section{Search strategy}

One reviewer (SML) searched information sources from inception to 16 August 2019 and social media. Search terms were derived from keywords found in the scoping search and identified exercises from social media: 'thoracic spine', 't-spine', 'mid back', 'upper back', 'trunk', 'thorax', 'strength training', 'exercises', 'stretching', 'mobility', 'power', 'phase 3','endurance ', 'motor control ', 'neuromuscular control', 'roll-outs', 'bridges', 'windmills', 'open book', 'deadlift', 'zercher squat', 'front squat', 'roman chair', 'bird dog', 'good morning', 'jefferson curl', 'y-lift', 'kettlebell swings', 'turkish get up', 'foam rolling', 'healthy participants', 'athletes or athletic', 'sporting or sport'. Where possible mesh terms, wildcards and limitations to humans, body part thoracic spine and age group were also used. We used the Boolean operators NOT for age groups children, paediatric, elderly and geriatric.

\section{Study selection}

Articles were stored and duplicates removed on Refworks. Articles were screened by one reviewer (SML) first by title and abstract and then by full-text review. In contrast to the database search, the yield through social media was considerable, with a single search (YouTube.com) for thoracic spine exercises yielding 1490000 results. From a consensus decision (SML, IT, NRH), it was agreed that where a search using predetermined keywords generated no new videos or images beyond 100 hits, the search was considered saturated and a new search initiated. All exercises were recorded along with a description of the exercise.

Following screening, all eligible sources were stored along with a detailed description of the exercise and its execution. Three reviewers (SML, IT and SL) evaluated all exercises independently and through a process of consensus agreed on final selection of included exercises based on content validity, 'the degree to which items of an instrument sufficiently represent the content domain', ${ }^{24}$ where the instrument is the exercise and the content domain the outcome and evaluated by experts, the latter differentiating this from face validity. ${ }^{24}$ Evaluation of all included exercises to determine eligibility involved evaluation of each source (textual and visual) as well as 'active physical performance of, and analysis' of the exercise by a specialist physiotherapist with $15+$ years of experience of strength and conditioning training (SML), an athlete and physiotherapist with $10+$ years of experience of strength and mobility training (IT) and strength and conditioning coach with $10+$ years of experience (SL). Final selection was based on an exercise having a primary outcome for example, mobility or motor control as determined by the expert reviewers.

Where similar exercises were identified from different sources, selection through consensus favoured exercises suitable for more than one sport and exercises which could be performed at different levels of intensity.
Additionally, selection included both functional and nonfunctional exercises, where functional exercises describes weight bearing or sport-specific exercises which can be performed in multiple planes of motion involving several joints ${ }^{1}$ and non-functional exercises describes exercises performed in partial weight-bearing positions moving in a single plain of motion involving few joints. ${ }^{1}$

\section{Data collection}

Reviewers (SML and IT) independently extracted relevant data using bespoke and piloted tables, with the third reviewer (NRH) checking for consistency and accuracy. Where the focus was primarily on the evaluation of the exercise, extracted data were restricted to that required to evaluate quality of source and inform the narrative synthesis.

\section{Data items}

Exercise name, broad description, links to source and thumbprint image were recorded. Exercises were grouped according to each focused outcome.

\section{Quality assessment and evaluation}

In the absence of guidance on quality assessment for social media resources ${ }^{20}$ and the inclusion of empirical and non-empirical sources, no formal risk of bias assessment was performed. Evidence was however evaluated based on level of evidence, where 1a represents a systematic review of randomised control trials through to level 5 representing expert opinion without critical appraisal. ${ }^{25}$ Overall level of evidence for each outcome was evaluated using grades of recommendation from the Oxford Centre for Evidence based Medicine (CEBM) where A: level 1 studies, B: level 2 or 3 studies, C: level 4 studies and D: level 5 studies. ${ }^{25}$

\section{Synthesis of results}

A narrative synthesis was conducted with exercises tabulated within the expert-derived framework for spinal-exercise classification. The synthesis allowed subclassification for static and dynamic exercises, functional and non-functional exercises, segmental, spinal, whole-body stabilisation/dissociation, pillar or segmental conditioning, pillar strength, stiffness or power development. ${ }^{1}$

\section{RESULTS}

From 2348 sources which included social media, database searches and other sources, exercises were identified and stored. Some studies from the databases included more than one exercise for consideration. Following removal of duplicates and review against eligibility criteria, 38 exercises (with variants) were included from all sources; 18 from articles and 20 from social media. Social media sources were mainly drawn from www.youtube.com. Where not available on YouTube, links to other social media sites (Facebook) were included. Agreement between researchers evaluating exercises was $100 \%$. 


\section{Characteristics of included sources}

All 38 exercises included individuals which 'fit' within that of an athletic population, with some evidence derived from database sources being sports specific for example, swimmers,${ }^{26}{ }^{27}$ golf, ${ }^{28}$ basketball players ${ }^{29}$ and climbers. ${ }^{30}$ Four studies were randomised control trials where thoracic exercise was just one component of an exercise intervention. ${ }^{16273031}$ One large cohort included thoracic exercises as part of a rehabilitation intervention in athletes with groin pain. ${ }^{32}$ A further study investigated intrarater and inter-rater reliability of five thoracic rotation measurement techniques. ${ }^{14}$ All other remaining sources were either from social media (YouTube $n=20$ and Facebook $n=2$ ), a review or evaluated as bench or 'first principles' research ${ }^{25}$ evaluating a movement or movement characteristic in samples of convenience.

Level of evidence

The majority of included sources were graded as level $5^{25}$ sources being either expert opinion (review articles or social media sources), first principles exploratory laboratory-based studies with small samples (range 8-31). More recent sources included, among others, a large cohort study $(\mathrm{n}=205)^{32}$ and four small trials (range
22-52), ${ }^{16} 283031$ where thoracic spine exercises formed a component part of an intervention. Agreement between reviewers was $100 \%$ following discussion.

\section{Level of evidence across outcomes}

For each exercise outcome, mobility, motor control, work capacity and strength, the overall body of evidence was rated as D, based on included sources being in the main derived from level 5 evidence $^{25}$ (see online supplementary file 1).

\section{Physical abilities}

Mobility exercises

Nine dynamic exercises (Non functional exercises being: 'Thoracic extension on foam roller', ${ }^{33} 34$ or ball', ${ }^{16}$ 'Kneeling thoracic spine extension stretch', ${ }^{34}$ Thoracic flexion quadruped with and without roller, ${ }^{35}{ }^{36}$ Sidelying side-flexion over Swiss ball, ${ }^{37}$ 'Sidelying thoracic rotation', 38 'Quadruped thoracic rotation', ${ }^{14} 39$ Squat with extension and rotation ${ }^{40}$ and, functional exercises being: Jefferson curl $^{41}$ and 'Jefferson curl $^{41}$ and 'Seat side flexion with/without rotation' ${ }^{42}$ ) aimed to improve thoracic mobility (see table 1) with three utilising the 'heel-sit' or an equivalent position as a means of 'fixing'

Table 1 Examples of mobility exercise

Mobility development (non-functional)

Thoracic extension on foam roller ${ }^{33} 34$ or ball $^{16}$

Kneeling thoracic spine extension stretch ${ }^{34}$

Thoracic flexion quadruped with and without roller ${ }^{35} 36$

Sidelying side-flexion over Swiss ball ${ }^{37}$

Sidelying thoracic rotation ${ }^{38}$ (illustrated)

Quadruped thoracic rotation ${ }^{14} 3439$

Squat with extension and rotation ${ }^{40}$

\section{Mobility development (functional)}

Jefferson curl ${ }^{41}$

Seated side flexion with/without rotation ${ }^{42}$ (illustrated)
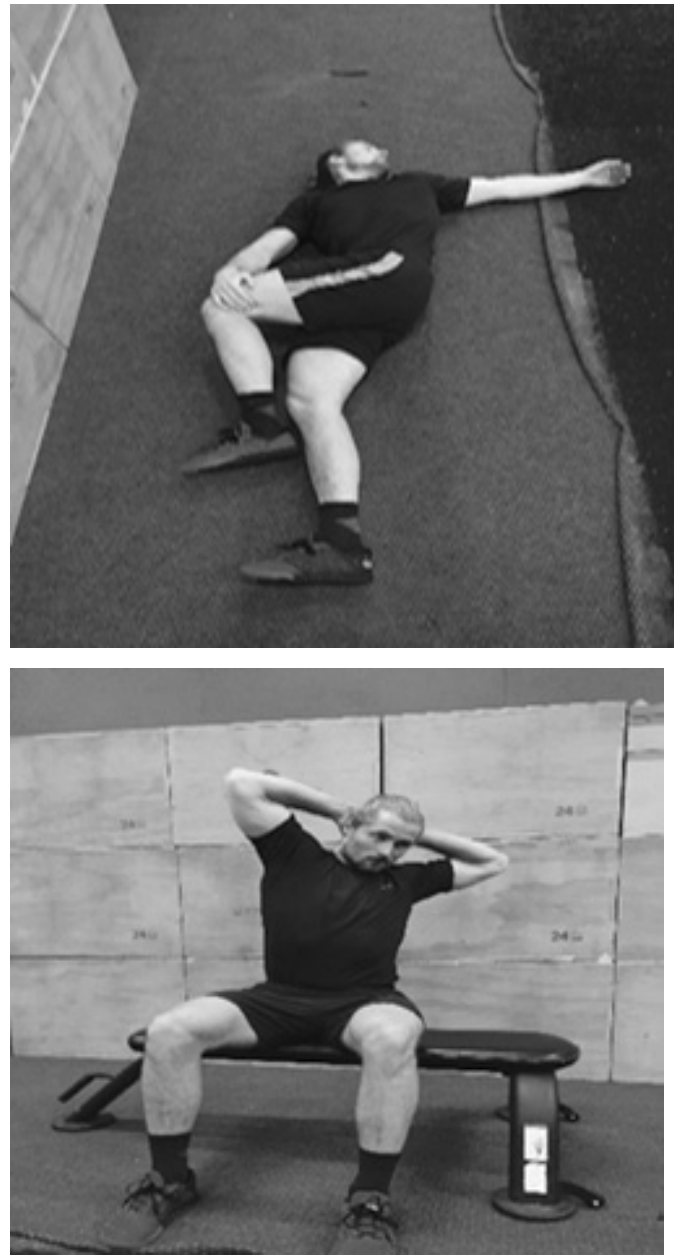
the lumbar spine to enable targeted thoracic spine motion. ${ }^{12}$ Many exercises rely on the integrity of other body regions to assist specificity to the thoracic spine for example, hip and knee flexion for exercises which involve heel sit or squat. Likewise, using the upper limb as a long lever in exercises such as squat with extension and rotation or sidelying thoracic rotation are predicated on unimpaired upper limb function. No studies have investigated effectiveness of thoracic spine exercise for improving mobility in any planes in an athletic population. More non-functional than functional exercises were identified which were partial weight bearing and involved single-plane motion. Detailed descriptions of each exercise and evaluation are included in online supplementary appendix 1 .

\section{Motor control exercises}

Seven exercises, two static ('Bird dog', ${ }^{28}$ 43-45 'Wall squat' ${ }^{4647}$ ) and five dynamic ('Flexion/extension control quadruped', ${ }^{48}$ 'Half circle in side lying', ${ }^{38}$ 'Sitting side flexion (mermaid)', ${ }^{49}$ 'Upper back rotation with lunges ${ }^{150}$ and 'Standing wood chop/chop and lift' ${ }^{50-53}$ ) were identified as specific for promoting motor control and maintaining spinal integrity during skilled movement (see table 2). A notable gap was exercises specific to segmental stabilisation. The seven exercises were reflective of three distinct subgroups based on their main aim of influencing a specific feature of motor control'spinal dissociation', 'segmental movement control' or 'whole body coordination'. 'Spinal dissociation exercises included 'Bird $\operatorname{dog}{ }^{28}{ }^{43-45}$ and 'Wall squat ${ }^{4647}$ to improve static control of the thoracic spine by maintaining a static neutral thoracic posture while moving other body regions. Segmental movement control exercises included 'Flexion/extension control quadruped', 'Half circle in side lying', ${ }^{38}$ 'Sitting side flexion (mermaid) ${ }^{49}$ with each aiming to improve dynamic control of thoracic spine movement around all three motion planes. Whole body coordination exercises included 'Upper back rotation with lunges' ${ }^{50}$ and 'Standing wood chop/chop and lift ${ }^{50-53}$ to improve dynamic control of thoracic spine movements in conjunction with movements of other parts of the kinetic chain. As with mobility, performance of many of the included exercises is dependent on the integrity and functional musculoskeletal capacity of other regions, for example, 'Standing wood chop/chop and lift'. Detailed descriptions of each exercise and evaluation are included in online supplementary appendix 2.

\section{Work capacity}

Eight 'static' pillar conditioning exercises ('Y-lift on bosu ball', ${ }^{26} 275455$ 'Pike, ${ }^{56} 57$ 'Kneeling power-wheel rollout or sliding mat', ${ }^{3057-59}$ 'Roman chair lateral holds', ${ }^{60}$ 'One arm inverted row', ${ }^{61} 62$ 'Windmills with kettlebells' ${ }^{,}{ }^{63}$ 'Lateral cable walkout', ${ }^{64}$ 'Kettlebell swing ${ }^{, 65}{ }^{66}$ ) aimed at improving static work capacity of the thoracic spine (ability to maintain a neutral spine with either the athlete's own bodyweight or external load working as an external perturbation force during a non-functional or functional task) ${ }^{1}$ were included (see table 3). Additionally, nine dynamic segmental conditioning exercises ('Upper back extension', ${ }^{67}$, V-ups', ${ }^{68}$ 'Half Turkish get-up, ${ }^{69}$ 'Lateral sit ups', ${ }^{31} 70$ 'W-sit ball rotation/ twister', 7172 'Standing thorax extensions', ${ }^{73}$ 'Kettlebell swing', ${ }^{65} 66$ 'Dumbell/kettlebell side bend" ${ }^{\text {'74 }}$ and 'W-sit ball rotation/twister ${ }^{72}$ ) aimed at improving dynamic work capacity of the thoracic spine (ability of sequentially producing or absorbing forces through the thoracic spine during non-functional or functional movement tasks) ${ }^{1}$ were included. Considerably, more so than for mobility and motor control performance of included work capacity exercises may be limited by impairments in functional capacity or integrity of other body regions. With some of the included exercises involving muscle activation with long levers (Y-lift on bosu ball, Superman), loading through upper limbs (Pike), or both (Windmills with kettlebell), there is considerable scope for exercise prescription to be personalised based on functional capacity and requirements of the sport. A high degree of kinaesthetic awareness is required to ensure specificity to the thoracic spine. Detailed descriptions of each exercise and evaluation are included in online supplementary appendix 3.

\section{Strength}

Seven exercises were included which aimed to improve strength in the thoracic spine and augment global power production ('Battle ropes', ${ }^{29} 7576$ 'Side medicine ball throws $^{72} 7778$ or stiffening to resisting outside forces, 'Front lever', ${ }^{30} 79$ 'Deadlift', 32 80-83 'Partner backwards fall', ${ }^{84}$ 'Side pull prowler', ${ }^{1}$ Partner push $^{85}$ ) thereby protecting the spine. ${ }^{1}$ (see table 4) Exercises prescription may usually include low intensity focusing more on neurological adaptions, or high intensity focusing more on morphological muscular adaptions. ${ }^{1}$ While the majority of exercises were rated functional that is, weight bearing, the only included multiplane exercise was the 'Side pull prowler', ${ }^{1}$ where the individual is in a forward and side flexed position. Just one exercise, the 'Front lever', ${ }^{79}$ was included for pillar strength development, although arguably not thoracic spine specific. Functional power development exercises included one for axial rotation and one flexion/extension, where the aim is to produce maximal sequential spinal force or torque in a functional position; a requirement for sports such as discus or hammer throw. For strength exercises, both a high degree of kinaesthetic awareness is required for specificity to the thoracic spine and dependent on the integrity and functional musculoskeletal capacity of other regions, for example, 'Side medicine ball throws'. 727778 Detailed descriptions of each exercise and evaluation are included in online supplementary appendix 4 .

\section{Evidence synthesis}

Table 5 synthesises evidence of mobility, motor control, work capacity and strengthening exercises within the 


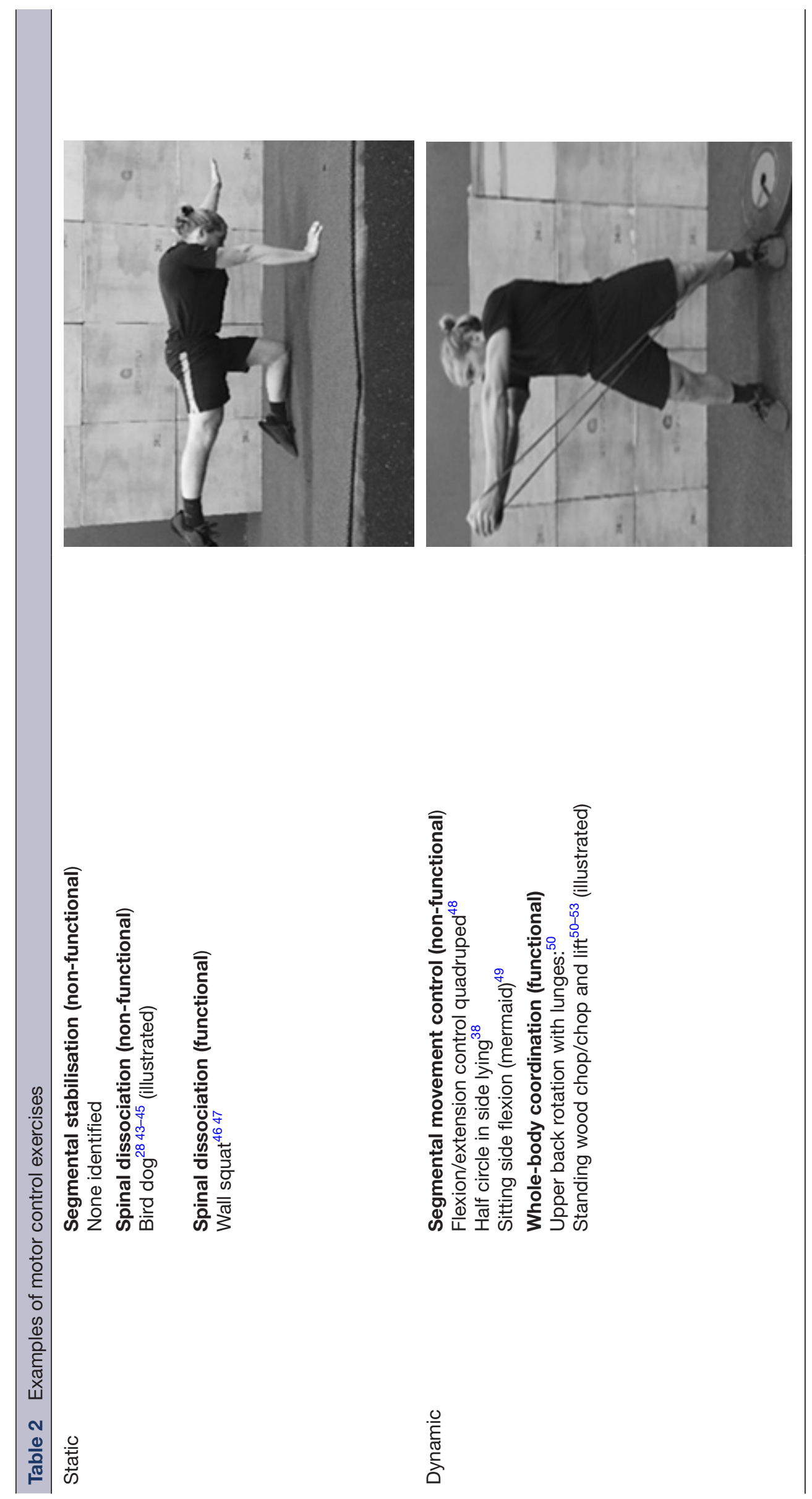


Table 3 Examples of work capacity exercises

$\begin{array}{ll}\text { Static } & \text { Pillar conditioning (non-functional) } \\ \text { Y-lift on Swiss ball, Superman } & \text { (illustrated) } \\ & \text { (ill 54 55 } \\ & \text { Pike } 5657 \\ & \text { Kneeling power-wheel rollout }^{30} 57-59 \\ & \text { Roman chair lateral holds } \\ & \text { One arm inverted row } \\ & \text { Pillar conditioning (functional) } \\ & \text { Kettlebell swing } \\ & \text { Windmills with } \text { kettlebell }^{63} \\ & \text { Lateral cable walk out }\end{array}$

Dynamic

\author{
Segmental conditioning (non-functional) \\ Upper back extension ${ }^{67}$ \\ V-ups ${ }^{68}$ \\ Half Turkish get-ups ${ }^{69}$ \\ Lateral sit ups ${ }^{3170}$ \\ W-sit ball rotation ${ }^{7172}$
}

Segmental conditioning (functional)

Standing thorax extensions ${ }^{73}$

Kettlebell swing ${ }^{656}$ (illustrated)

Dumbbell/kettlebell side bends ${ }^{74}$

W-sit ball rotation ${ }^{71} 72$

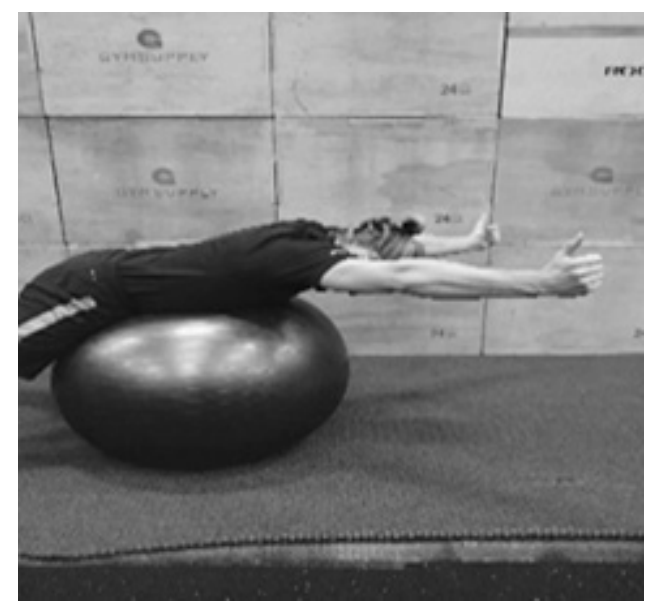

classification framework. Although all outcomes are rated as level D evidence, the synthesis illustrates the scope and nature of exercises being used in practice by 'experts' or exploratory, research based on first principles. ${ }^{25}$ Exercises are named either according to start position and motion or by an adopted name for example, 'mermaid', with the latter requiring a detailed evaluation by experts to 'correctly' classify the exercise accordingly to its aim focused to the thoracic spine.

With respect to static spinal displacement, empirical evidence sources exist for motor control, work capacity and strengthening although other sources were required to ensure inclusion of exercises in the frontal plane for example, 'Roman chair lateral hold' (work capacity) and 'Partner push' (strengthening). For dynamic spinal displacement, considerably more exercises were drawn from social media sources especially in terms of mobility exercises to enable inclusion of single and multiplane movements, for example, 'Squat with extension and rotation', ${ }^{40}$ or 'Seated side flexion with/without rotation'. ${ }^{42}$

\section{DISCUSSION}

This is the first comprehensive review and synthesis of thoracic spine exercises for use in sporting populations. Evaluation and adoption of the spinal exercise classification system ${ }^{1}$ may assist practitioners' thoracic spine exercise prescription for athletes. Appraisal of the intended outcomes for each exercise (mobility, motor control, work capacity or strength) provides a foundation for future research; recognising that description of an exercise is one dimension of exercise prescription. Further research is now required to investigate the effectiveness and optimal dose (frequency, repetitions, hold duration and speed) to realise improvements in meaningful patient reported and performance-based outcomes such as performance, and/or pain; something we have some good evidence for with passive interventions directed to the thoracic spine ${ }^{8687}$ but not yet for active interventions. Drawing from social media as well as empirical sources has enabled an inclusive review, capturing exercises widely used within the field of 'strengthening and conditioning'. The broad scope of the review has enabled the inclusion of exercises which are being taught and used in practice which currently have no supporting empirical evidence, paving the way for more targeted research into clinical effectiveness.

\section{Mobility}

A range of exercises for thoracic mobility exist, with social media sources offering diversity in range of exercises, 
Table 4 Examples of strengthening exercises

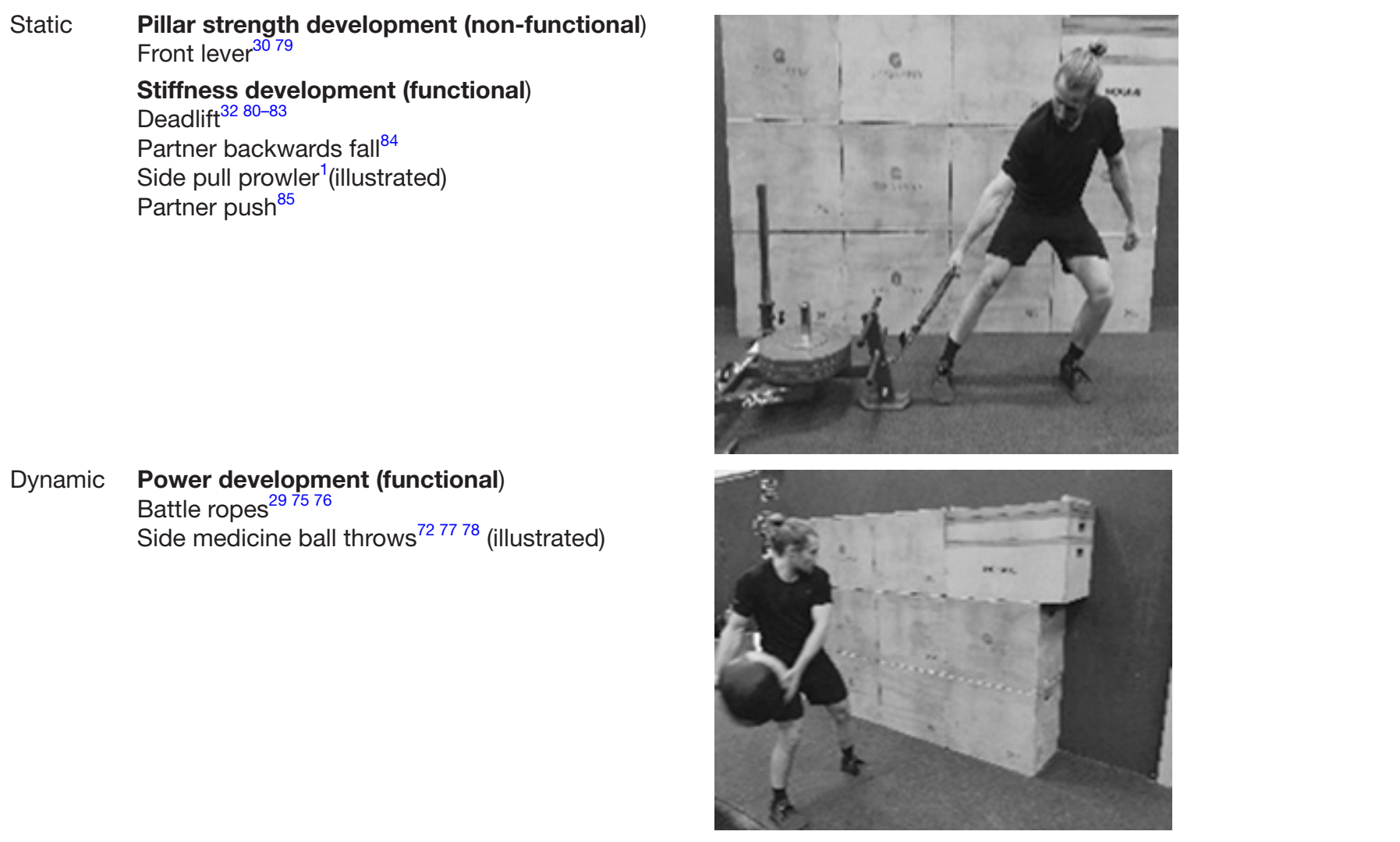

and reinforcing the merit of drawing on other evidence sources outside databases. Notwithstanding the level of evidence for individual sources or across the outcomes collation of exercises around different axes and movement planes offer practitioners a foundation for precision rehabilitation in exercise prescription for development of mobility. Given the natural stiffness of this region, many of these exercises are reliant on the large proximal and peripheral joints for stability for example, kneel position, or to generate long levers for example, extended upper limbs to specifically target the thoracic spine. Such exercises may be suitable for upper or lower limb injury prevention, but may be more challenging in early rehabilitation where symptom reproduction may impact optimal body positioning or ability to make best use of long levers. In view of the relatively limited range of exercises, precision training and rehabilitation in this region require further critical consideration of the following influencing factors, including posture, ${ }^{88} 89$ age ${ }^{90}$ sportspecific requirements, positioning relative to other linked body regions ${ }^{89}$ and dose-response.

\section{Motor control}

Few exercises were identified that specifically targeted thoracic motor control, with overlap observed with those used for the lumbar spine. Further critical consideration of a common language would assist reasoning where reference to 'neutral trunk position' is poorly defined and does not capture the 'sport-specific position' for the thoracic spine. There are many deep local thoracic muscles; we have very little knowledge in terms of their contribution to motor control for example, Rotatores, Semispinalis thoracis. The inherent stability of the thoracic spine ${ }^{90}$ and lack of differential muscle activation during function $^{91}$ highlights the potential for these exercises having a role in movement control coordination using feedback and feed-forward control mechanisms linked to proprioception or sensorimotor control; scientific underpinning is however currently lacking. Motor control deficits and interventions are widely evidenced in the cervical and lumbar spine although little evidence in the thoracic spine. ${ }^{8692-94}$ Adopting the term 'sensorimotor control' as has been noted in a recent study ${ }^{31}$ acknowledges a potentially greater role for the thoracic spine in proprioception; a requirement for sporting performance and recognises the contribution of the many sensory mechanoreceptors located in thoracic joints and muscles via muscle spindles. ${ }^{95-98}$ Impaired proprioception has been identified in healthy individuals, individuals with low back pain during a functional task ${ }^{99}$ and with repetitive activities or with fatigue $^{100}$ supporting the need for further research in the thoracic spine.

\section{Work capacity}

Synonymous with local muscular endurance, ${ }^{1}$ work capacity exercises included in the earlier spinal classification $^{1}$ (non-functional plank (front/side), functional single leg loading, half kneel load, single leg load) also 


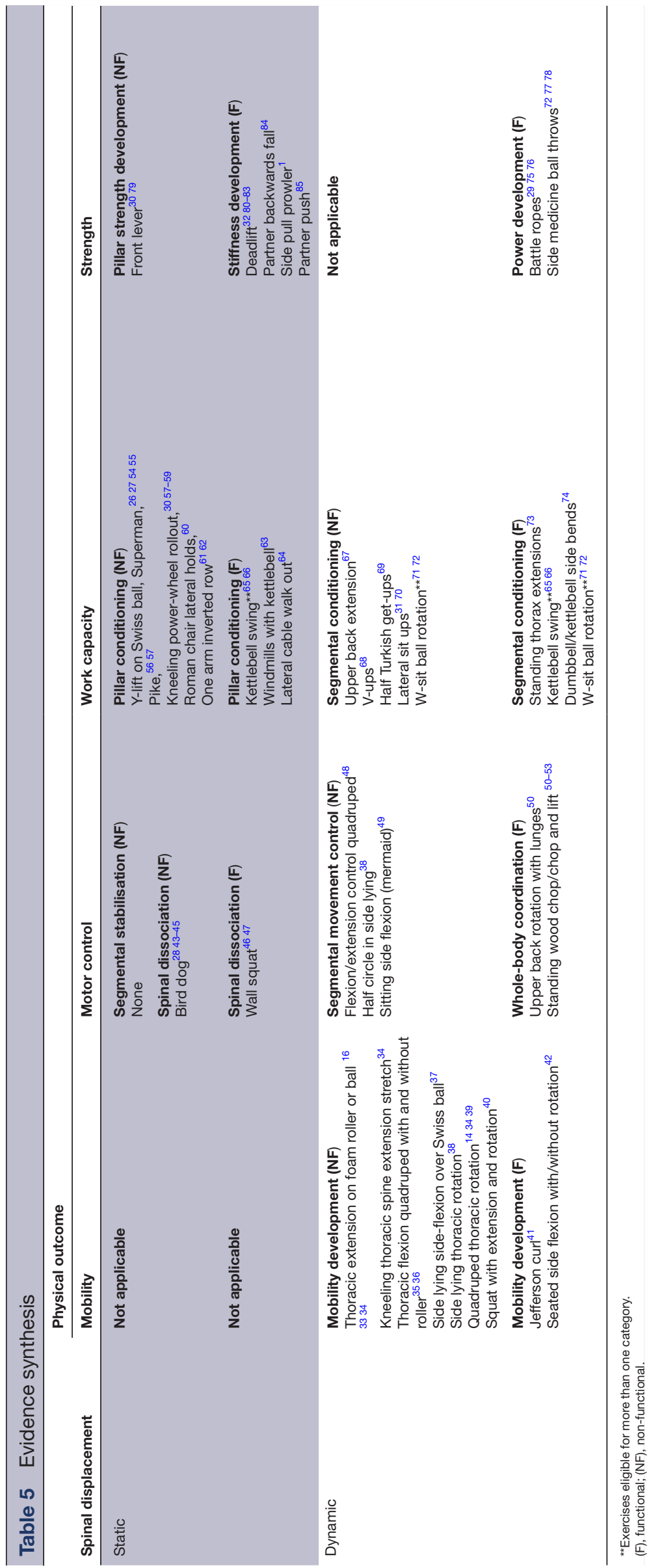


met eligibility requirements for this review. This reflects a lack of differentiation between the thoracic and lumbar spine in studies of the 'trunk'. Exercises included in the current review preferentially bias the upper trunk and target work capacity development around axial rotation (windmills with kettlebells, one arm inverted row) to reflect the biomechanical differences across spinal regions. ${ }^{101}$ Similarly, segmental conditioning exercises preferentially target the thoracic spine, with many dependent on optimal functioning of shoulder and upper limb given the weight-bearing or load bearing nature of the exercises, potentially limiting the relevance to athletes presenting with upper limb impairment. Many of the included work capacity and strength exercises were poorly described in identified sources. Future research should seek to explore their validity in targeting the thoracic spine and investigate the influence of manipulating parameters within exercise prescription influences muscle activation and exercise kinematics in an athletic population.

\section{Strength}

Strength requirements in the thoracic spine region relate to augmenting global power production (generate and mediate forces) or protecting the spine (moderate) through stiffening. Included exercises are generic and do not fully capture the need for exercises with multiplane/axes motions to better reflect the demands of sport where specific requirements should inform posture and motion, reinforcing the importance of personalising exercise prescription. Differentiation of 'work capacity' and 'strength' is not widely recognised within the literature although does usefully introduce a further dimension to support evidence informed clinical reasoning in exercise prescription. For some exercises, where descriptions are incomplete, a small modification can affect classification of the exercise, for example static or dynamic spinal displacement is feasible with a kettlebell swing. This is also reflected in defining an exercise functional or nonfunctional where $\mathrm{W}$-sit rotation would only be considered functional for seated sports.

\section{Implications}

While providing a framework for use in practice, further work is required to tailor this to the requirements of different sports and functional requirements of each athlete. Contrary to a reductionist approach, this classification framework incorporating parameters such as function versus non-function, static versus dynamic and pillar versus segmental facilitates critical clinical reasoning in personalised thoracic spine exercise prescription. For the purpose of this review, exercises were included that best 'fit' the classifications within the framework; however, it is noted that where prescribed for a particular sport the exercise had the potential to overlap categories or, by changing dose (loading, frequency, etc) for functional exercises. Clinically, this is relevant where the desired outcomes may involve development of more than one domain for example, mobility and work capacity may be relevant for endurance sports involving repeated movements through range such as swimming. Furthermore, the effectiveness of any given exercises has not yet been established with this review offering a foundation from which this can be investigated for each exercise.

\section{Future research}

Research is now required to investigate the validity of included exercises linked to the intended outcomes and to build on this to inform thoracic spine exercise prescription in sport. Understanding how variants such as loading and unloading, ageing and postural positions may impact on exercise prescription is also required to further inform precision rehabilitation. Research is also needed to investigate the effectiveness of included exercises in practice. Conventional approaches with repeated movements or sustained stretches based on empirical evidence and drawn from the lower limb muscles ${ }^{102}$ to promote spinal mobility do not recognise the unique tissue properties of different thoracic spine structures (joint, muscle and fascia). While static, dynamic and precontraction stretches are generally effective in increasing flexibility ${ }^{102}$ with restoration of lumbar spine flexibility demonstrated in a number of studies ${ }^{103} 104$ transferability to this inherently stable 'stiff' spinal region ${ }^{101}$ is difficult and manipulating of dosage including prolonged 'stretches' to maximise creep deformation or load-relaxation ${ }^{105}$ may be required. Consideration of parameters such as speed, range, starting positions would further strengthen the value of this framework in practice, drawing on principles of motor learning to influence 'neuroplasticity' with targeted exercise prescription. ${ }^{106}$

\section{Strengths and limitations}

This review utilising multidisciplinary and methodological expertise with transparency of methods enables us to have confidence in its findings. Although not yet extensively validated, the adoption of the cross discipline expert derived spinal exercise classification system, has enabled its evolution to the thoracic spine, with consistency in terminology and language within the evaluation. Drawing on social media enabled breadth of resources to be captured, recognising the paucity of thoracic spine specific research. Findings are relevant to all sports, although personalisation is required to consider specific requirements and demands. Findings may be used to inform further research in thoracic spine exercise prescription and place a spotlight on the thoracic spine as a critical component of the functional kinetic chain.

Given the volume of resources available, review of all social media sources was not feasible and some exercises may therefore have been omitted. With one reviewer completing the searches and screening, and inconsistencies in the use of language to describe exercise in the thoracic spine may also have contributed to some exercises being overlooked, with terms such as torso, ${ }^{64} 107$ trunk $^{910108-115}$ and upper body ${ }^{116}$ used in the literature. 
Appraisal of quality of resources was not possible in the absence of guidance on critical appraisal of social media sources, although drawing on the CEBM framework enabled an evaluation of individual sources and each outcome. No attempts were made to prioritise selection based on 'popularity' of specific exercises as hits for each were not recorded; this may have been useful to inform recommendations for research prioritisation going forward based on popularity. Finally, although a protocol was developed by the authors, this was not published or registered.

\section{CONCLUSION}

This rigorous synthesis provides a framework for practitioners to clinically reason outcome focused thoracic spine exercise prescription for outcomes of mobility, motor control, work capacity and strength. Drawing on the breadth of available resources, this innovative inclusive review of exercises can now be used to inform future focused research to develop greater knowledge and understanding of thoracic spine exercise prescription, specifically to investigate the effectiveness of the included exercises on meaningful outcomes.

\section{Twitter Nicola R Heneghan @Nicola Heneghan}

Contributors Conception and design: NRH, SML and AR. Data collection: NRH, SML and IT. Data analysis: NRH, SML, IT and SL. Data interpretation: NRH, SML, IT, SL and AR. Manuscript contribution: NRH, SML, IT, SL and AR. NRH is the guarantor.

Funding The authors have not declared a specific grant for this research from any funding agency in the public, commercial or not-for-profit sectors.

\section{Competing interests None declared.}

Patient consent for publication Obtained.

Provenance and peer review Not commissioned; externally peer reviewed.

Data availability statement All data relevant to the study are included in the article or uploaded as supplementary information.

Open access This is an open access article distributed in accordance with the Creative Commons Attribution Non Commercial (CC BY-NC 4.0) license, which permits others to distribute, remix, adapt, build upon this work non-commercially, and license their derivative works on different terms, provided the original work is properly cited, appropriate credit is given, any changes made indicated, and the use is non-commercial. See: http://creativecommons.org/licenses/by-nc/4.0/.

\section{ORCID iDs}

Nicola R Heneghan http://orcid.org/0000-0001-7599-3674

Alison Rushton http://orcid.org/0000-0001-8114-7669

\section{REFERENCES}

1 Spencer S, Wolf A, Rushton A. Spinal-Exercise prescription in sport: classifying physical training and rehabilitation by intention and outcome. J Athl Train 2016;51:613-28.

2 Heneghan NR, Rushton A. Understanding why the thoracic region is the 'Cinderella' region of the spine. Man Ther 2016;21:274-6.

3 Kaczmarek PK, Lubiatowski P, Cisowski P, et al. Shoulder problems in overhead sports. Part I - biomechanics of throwing. Pol Orthop Traumatol 2014;79:50-8.

4 Fujii R, Sakaura H, Mukai Y, et al. Kinematics of the lumbar spine in trunk rotation: in vivo three-dimensional analysis using magnetic resonance imaging. Eur Spine J 2007;16:1867-74.

5 Edmondston S, Ferguson A, Ippersiel P, et al. Clinical and radiological investigation of thoracic spine extension motion during bilateral arm elevation. J Orthop Sports Phys Ther 2012;42:861-9.

6 Theodoridis D, Ruston S. The effect of shoulder movements on thoracic spine 3D motion. Clinical Biomechanics 2002;17:418-21.
7 Heneghan NR, Webb K, Mahoney T, et al. Thoracic spine mobility, an essential link in upper limb kinetic chains in athletes: a systematic review. Trans/ Sports Med 2019;00:1-15.

8 Tsang SMH, Szeto GPY, Lee RYW. Normal kinematics of the neck: the interplay between the cervical and thoracic spines. Man Ther 2013;18:431-7.

9 Aragon VJ, Oyama S, Oliaro SM, et al. Trunk-rotation flexibility in collegiate softball players with or without a history of shoulder or elbow injury. J Athl Train 2012;47:507-15.

10 Oyama S, Yu B, Blackburn JT, et al. Improper trunk rotation sequence is associated with increased maximal shoulder external rotation angle and shoulder joint force in high school baseball pitchers. Am J Sports Med 2014;42:2089-94.

11 Sueki DG, Cleland JA, Wainner RS. A regional interdependence model of musculoskeletal dysfunction: research, mechanisms, and clinical implications. J Man Manip Ther 2013;21:90-102.

12 Bucke J, Spencer S, Fawcett L, et al. Validity of the digital Inclinometer and iPhone when measuring thoracic spine rotation. $J$ Athl Train 2017;52:820-5.

13 Heneghan N, Baker G, Thomas K, et al. The influence of sedentary behaviour and physical activity on thoracic spinal mobility in young adults: an observational study. BMJ Open 2018;8.

14 Johnson KD, Kim K-M, Yu B-K, et al. Reliability of thoracic spine rotation range-of-motion measurements in healthy adults. J Athl Train 2012;47:52-60.

15 Ganer N, Kulandaivelan S, Malik M, et al. Thoracic spinal manual therapy and regional interdependence: a review. International Journal of Health Sciences and Research 2016;6:337-44.

16 Nakamaru K, Aizawa J, Kawarada K, et al. Immediate effects of thoracic spine self-mobilization in patients with mechanical neck pain: a randomized controlled trial. J Bodyw Mov Ther 2019;23:417-24.

17 Wainner RS, Whitman JM, Cleland JA, et al. Regional interdependence: a musculoskeletal examination model whose time has come. J Orthop Sports Phys Ther 2007;37:658-60.

18 Andersson SH, Bahr R, Clarsen B, et al. Preventing overuse shoulder injuries among throwing athletes: a cluster-randomised controlled trial in 660 elite handball players. Br J Sports Med 2017;51:1073-80.

19 Dissemination CfRa. Systematic Reviews: CRD's Guidance for Undertaking Reviews in Healthcare. CRD University of York, York Publishing Services Ltd, 2009.

20 Skiba D. Evaluation tools to appraise social media and mobile applications. Informatics 2017;4:32.

21 Moher D, Liberati A, Tetzlaff J, et al. Preferred reporting items for systematic reviews and meta-analyses: the PRISMA statement. PLoS One 2009;6:e1000097.

22 Cooke A, Smith D, Booth A. Beyond PICO: the spider tool for qualitative evidence synthesis. Qual Health Res 2012;22:1435-43.

23 De Mey K, Danneels L, Cagnie B, et al. Scapular muscle rehabilitation exercises in overhead athletes with impingement symptoms: effect of a 6-week training program on muscle recruitment and functional outcome. Am J Sports Med 2012;40:1906-15.

24 Zamanzadeh V, Ghahramanian A, Rassouli M, et al. Design and implementation content validity study: development of an instrument for measuring patient-centered communication. $J$ Caring Sci 2015;4:165-78.

25 Medicine CfE-B. Oxford centre for evidence-based medicine levels of evidence, 2009. Available: https://www.cebm.net/2009/06/ oxford-centre-evidence-based-medicine-levels-evidence-march2009/

26 Konin J, Barany M. Upper extremity and trunk stabilization exercises for swimmers. Athl Ther Today 2005;10:30-1.

27 Lynch SS, Thigpen CA, Mihalik JP, et al. The effects of an exercise intervention on forward head and rounded shoulder postures in elite swimmers. Br J Sports Med 2010;44:376-81.

28 Lehman GJ. Resistance training for performance and injury prevention in golf. $J$ Can Chiropr Assoc 2006;50:27-42.

29 Chen $\mathrm{W}-\mathrm{H}$, Wu H-J, Lo S-L, et al. Eight-Week battle rope training improves multiple physical fitness dimensions and shooting accuracy in collegiate Basketball players. $J$ Strength Cond Res 2018;32:2715-24.

30 Saeterbakken AH, Loken E, Scott S, et al. Effects of ten weeks dynamic or isometric core training on climbing performance among highly trained climbers. PLOS One 2018;13:e0203766.

31 Mueller S, Engel T, Mueller J, et al. Sensorimotor exercises and enhanced trunk function: a randomized controlled trial. Int J Sports Med 2018;39:555-63.

32 King E, Franklyn-Miller A, Richter C, et al. Clinical and biomechanical outcomes of rehabilitation targeting intersegmental 
control in athletic groin pain: prospective cohort of 205 patients. $\mathrm{Br}$ J Sports Med 2018;52:1054-62.

33 Durall CJ. Therapeutic exercise for athletes with nonspecific neck pain. Sports Health 2012;4:293-301.

34 Howe L, Read P. Thoracic spine function: assessment and self management. Professional Journal of Strength and Conditioning 2015;39:21-31.

35 Richardson S. Myo-Fit thoracic flexion exercise, 2014. Available: https://www.youtube.com/watch?v=vSqeeafP4UY [Accessed 9 Feb 2018].

36 Team Golf Loopy. Golf mobility exercise. thoracic spine flexion, 2013. Available: https://www.youtube.com/watch?v=j8OuA46BT6Q [Accessed 9 Feb, 2018].

37 Stadler A. Ball stretch group lateral flexion, 2017. Available: https:// www.youtube.com/watch?v=RaKoWJH1Z0A [Accessed 9 Feb 2018].

38 Kinetic Sports Rehab. How to do side lying thoracic rotations, 2015. Available: https://www.youtube.com/watch?v= twGnMnUapAs [Accessed 9 Feb 2018].

39 Mclaughlin G. Quadruped thoracic spine rotation, 2015. Available: https://www.youtube.com/watch?v=z2zv52617M8 [Accessed 9 Feb 2018].

40 Abnormal Beings. Squat with extension/rotation. Available: https:// www.youtube.com/watch?v=P5IQjKRo934 [Accessed 2017].

41 moveSKILL. Instructional: Jefferson curl. Available: https://www. youtube.com/watch?v=koi9dAJLWcE [Accessed 9 Feb 2018].

42 Fieldwork Health. Thoracic seated rotation + side flexion, 2015 Available: https://www.youtube.com/watch?v=-Mpiy5qa8B8 [Accessed 9 Feb 2018].

43 Callaghan JP, Gunning JL, McGill SM. The relationship between lumbar spine load and muscle activity during extensor exercises. Phys Ther 1998;78:8-18.

44 McGill SM, Karpowicz A. Exercises for spine stabilization: motion/ motor patterns, stability progressions, and clinical technique. Arch Phys Med Rehabil 2009;90:118-26.

45 Willardson JM, Behm DG, Huang SY, et al. A comparison of trunk muscle activation: ab circle vs. traditional modalities. $J$ Strength Cond Res 2010;24:3415-21.

46 Chiu LZF, Burkhardt E. A teaching progression for squatting exercises. Strength Cond J 2011;33:46-54.

47 Myer GD, Kushner AM, Brent JL, et al. The back squat: a proposed assessment of functional deficits and technical factors that limit performance. Strength Cond J 2014;36:4-27.

48 StrengthSide. Thoracic spine exercise and full back extension, 2017. Available: https://www.youtube.com/watch?v= MQuIPwH18OI [Accessed 9 Feb 2018].

49 MOVEMENTmCoLab. Mermaid on the reformer for thoracic mobility, 2016. Available: https://www.youtube.com/watch?v= YUEjgPdWmXs [Accessed 9 Feb 2018].

50 Zemková E, Cepková A, Uvaček M, et al. A novel method for assessing muscle power during the standing cable wood CHOP exercise. J Strength Cond Res 2017;31:2246-54.

51 Dale RB MD. Proprioceptive neuromuscular facilitation for trunk mobility and strength. Ath/ Ther Today 2009;14:26-9.

52 Palmer TG, Uhl TL. Interday reliability of peak muscular power outputs on an isotonic dynamometer and assessment of active trunk control using the CHOP and lift tests. J Athl Train 2011;46:150-9.

53 Voight ML, Hoogenboom BJ, Cook G. The CHOP and lift reconsidered: integrating neuromuscular principles into orthopedic and sports rehabilitation. N Am J Sports Phys Ther 2008;3:151-9.

54 Behm DG, Leonard AM, Young WB, et al. Trunk muscle electromyographic activity with unstable and unilateral exercises. $J$ Strength Cond Res 2005;19:193-201.

55 Comfort P, Pearson SJ, Mather D. An electromyographical comparison of trunk muscle activity during isometric trunk and dynamic strengthening exercises. J Strength Cond Res 2011;25:149-54.

56 Escamilla RF, Lewis C, Bell D, et al. Core muscle activation during Swiss ball and traditional abdominal exercises. J Orthop Sports Phys Ther 2010;40:265-76.

57 Escamilla RF, Babb E, DeWitt R, et al. Electromyographic analysis of traditional and nontraditional abdominal exercises: implications for rehabilitation and training. Phys Ther 2006;86:656-71.

58 Escamilla RF, McTaggart MSC, Fricklas EJ, et al. An electromyographic analysis of commercial and common abdominal exercises: implications for rehabilitation and training. $J$ Orthop Sports Phys Ther 2006;36:45-57.

59 Hildenbrand K, Noble L. Abdominal muscle activity while performing Trunk-Flexion exercises using the AB roller, ABslide,
FitBall, and conventionally performed trunk Curls. J Athl Train 2004;39:37-43.

60 Workout W. How to do at Roman chair lateral hold, 2016. Available: https://www.youtube.com/watch?v=xuiipY3L-Xg [Accessed 9 Feb 2018].

61 McGill SM, Cannon J, Andersen JT. Muscle activity and spine load during pulling exercises: influence of stable and labile contact surfaces and technique coaching. Journal of Electromyography and Kinesiology 2014;24:652-65.

62 Saeterbakken A, Andersen V, Brudeseth A, et al. The effect of performing bi- and unilateral row exercises on core muscle activation. Int J Sports Med 2015;36:900-5.

63 Onnit. Kettlebell exercise: Windmill, 2015. Available: https://www. youtube.com/watch?v=ITSmgn_BQgY [Accessed 9 Feb 2018].

64 McGill SM, Karpowicz A, Fenwick CMJ, et al. Exercises for the torso performed in a standing posture: spine and hip motion and motor patterns and spine load. J Strength Cond Res 2009;23:455-64.

65 Beardsley C, Contreras B. The role of Kettlebells in strength and conditioning. Strength Cond J 2014;36:64-70.

66 McGill SM, Marshall LW, Swing K. Kettlebell swing, snatch, and bottoms-up carry: back and hip muscle activation, motion, and low back loads. J Strength Cond Res 2012;26:16-27.

67 togo H. Upper back extension 1 -hep2go, 2012. Available: https:// www.youtube.com/watch?v=EFKUTYcRjXU [Accessed 9 Feb, 2018].

68 LivestrongWoman. Medicine ball V-Up, 2014. Available: https:// www.youtube.com/watch?v=7MY2agzydDw [Accessed 9 Feb 2018].

69 Strongfirst. Turkish Get-Up basics. Available: https://www.youtube. $\mathrm{com} /$ watch?v=0bWRPC49-KI. [Accessed 2015].

70 Konrad P, Schmitz K, Denner A. Neuromuscular evaluation of Trunk-Training exercises. J Athl Train 2001;36:109-18.

$71 \mathrm{~S} \varnothing \mathrm{BE}$, Donath L, Roth R, et al. Exercise-Induced trunk fatigue decreases double Poling performance in well-trained cross-country skiers. Eur J Appl Physiol 2018;118:2977-2087.

72 Stodden DF, Campbell BM, Moyer TM. Comparison of trunk kinematics in trunk training exercises and throwing. J Strength Cond Res 2008;22:112-8.

73 Contreras B. 8 great thoracic extensor exercises, 2013. Available: https://www.youtube.com/watch?v=iQWOC-T3I6Q [Accessed 9 Feb 2018].

74 Howcast. How to do a dumbbell side bend ab Workout, 2012. Available: https://www.youtube.com/watch?v=dL9ZzqtQI5c [Accessed 9 Feb 2018].

75 Brewer W, Kovacs R, Hogan K, et al. Metabolic responses to a Battling rope protocol performed in the seated or stance positions. $J$ Strength Cond Res 2018;32:3319-25.

76 Bryant A. Beginner battle rope Workout, 2015. Available: https:// www.youtube.com/watch?v=658VcTBuovQ [Accessed $9 \mathrm{Feb}$ 2018].

77 Ikeda Y, Miyatsuji K, Kawabata K, et al. Analysis of trunk muscle activity in the side medicine-ball throw. J Strength Cond Res 2009;23:2231-40

78 Vera-Garcia F, Ruiz-Pérez I, Barbado D, et al. Trunk and shoulder EMG and lumbar kinematics of medicine-ball side throw and side catch and throw. European Journal of Human Movement 2014;33:93-109.

79 Bondi M. Front lever secrets tutorial by world record holder Marcus Bondi Calisthenics, 2015. Available: https://www.youtube.com/ watch?v=s9B1gYcGErQ [Accessed 9 Feb 2018].

80 Andersen V, Fimland MS, DA M, et al. Electromyographic comparison of Barbell Deadlift, Hex bar Deadlift and hip Thrust exercises: a cross-over study. J Strength Cond Res 2017:39:97-104.

81 Chulvi-Medrano I, García-Massó X, Colado JC, et al. Deadlift muscle force and activation under stable and unstable conditions. $J$ Strength Cond Res 2010;24:2723-30.

82 Lanham SN CJ, Chrysosferidis PMS, Szekely B, et al. Exercise technique. deficit Deadlift. Strength \& Conditioning Journal 2019;41:115-9.

83 Nuzzo JL, McCaulley GO, Cormie P, et al. Trunk muscle activity during stability ball and free weight exercises. J Strength Cond Res 2008;22:95-102.

84 institutt N-Ni. Hensikten er å få sterkere skuldre, 2017. Available: https://www.facebook.com/nimiullevaal/videos/ 1468232699899107/ [Accessed 9 Feb 2018].

85 Physiotherapy R. partner push, 2017. Available: https:// www.facebook.com/RethinkingPhysiotherapy/videos/ 1469574713073100/ [Accessed 9 Feb 2018]. 
86 Blanpied PR, Gross AR, Elliott JM, et al. Clinical practice guidelines linked to the International classification of functioning, disability and health from the orthopaedic section of the American physical therapy association. JOSPT 2017;47:A1-83.

87 Salom-Moreno J, Ortega-Santiago R, Cleland JA, et al. Immediate changes in neck pain intensity and widespread pressure pain sensitivity in patients with bilateral chronic mechanical neck pain: a randomized controlled trial of thoracic Thrust manipulation vs Non-Thrust mobilization. J Manipulative Physiol Ther 2014;37:312-9.

88 Edmondston SJ, Aggerholm M, Elfving S, et al. Influence of posture on the range of axial rotation and coupled lateral flexion of the thoracic spine. J Manipulative Physiol Ther 2007;30:193-9.

89 Edmondston S, Waller R, Vallin P, et al. Thoracic spine extension mobility in young adults: influence of subject position and spinal curvature. J Orthop Sports Phys Ther 2011;41:266-73.

90 Edmondston SJ, Singer KP. Thoracic spine: anatomical and biomechanical considerations for manual therapy. Man Ther 1997;2:132-43.

91 Lee L-J, Coppieters MW, Hodges PW. En bloc control of deep and superficial thoracic muscles in sagittal loading and unloading of the trunk. Gait Posture 2011;33:588-93.

92 Gross AR, Paquin JP, Dupont G, et al. Exercises for mechanical neck disorders: a cochrane review update. Man Ther 2016;24:25-45.

93 Machado LAC, Kamper SJ, Herbert RD, et al. Analgesic effects of treatments for non-specific low back pain: a metaanalysis of placebo-controlled randomized trials. Rheumatology 2009;48:520-7.

94 Saragiotto BT, Maher CG, Yamato TP, et al. Motor control exercise for chronic non-specific low-back pain. Cochrane Database Syst Rev 2016;21.

95 Aman JE, Elangovan N, Yeh I-L, et al. The effectiveness of proprioceptive training for improving motor function: a systematic review. Front Hum Neurosci 2014;8:1075

96 Lee L-J, Coppieters MW, Hodges PW. Anticipatory postural adjustments to arm movement reveal complex control of paraspinal muscles in the thorax. J Electromyogr Kinesiol 2009;19:46-54.

97 Lee L-J, Coppieters MW, Hodges PW. Differential activation of the thoracic multifidus and longissimus thoracis during trunk rotation. Spine 2005;30:870-6.

98 vDP ME, Veeger DJ, van Dieën JH. Effects of vision and lumbar posture on trunk neuromuscular control. $J$ Biomech 2015;48:298-303.

99 Hidalgo B, Gobert F, Bragard D, et al. Effects of proprioceptive disruption on lumbar spine repositioning error in a trunk forward bending task. J Back Musculoskelet Rehabil 2013;26:381-7.

100 Jubany J, Danneels L, Angulo-Barroso R. The influence of fatigue and chronic low back pain on muscle recruitment patterns following an unexpected external perturbation. BMC Musculoskelet Disord 2017;18:161.
101 Borkowski SL, Tamrazian E, Bowen RE, et al. Challenging the conventional standard for thoracic spine range of motion. JBJS Reviews 2016;4:1-511.

102 Page P. Current concepts in muscle stretching for exercise and rehabilitation. Int J Sports Phys Ther 2012;7:109-19.

103 Battaglia G, Bellafiore M, Caramazza G, et al. Changes in spinal range of motion after a flexibility training program in elderly women. Clin Interv Aging 2014;9:653-60.

104 Kuukkanen T, Mälkiä E. Effects of a three-month therapeutic exercise programme on flexibility in subjects with low back pain. Physiother Res Int 2000;5:46-61.

105 Toosizadeh N, Nussbaum MA, Bazrgari B, et al. Load-Relaxation properties of the human trunk in response to prolonged flexion: measuring and modeling the effect of flexion angle. PLoS One 2012;7:e48625.

106 Snodgrass SJ, Heneghan NR, Tsao H, et al. Recognising neuroplasticity in musculoskeletal rehabilitation: a basis for greater collaboration between musculoskeletal and neurological physiotherapists. Man Ther 2014;19:614-7.

107 Hopper L, Chan C, Wijsman S, et al. Torso and bowing arm three-dimensional joint kinematics of elite Cellists: clinical and Pedagogical implications for practice. Med Probl Perform Art 2017;32:85-93.

108 Campbell A, O'Sullivan P, Straker L, et al. Back pain in tennis players: a link with lumbar serve kinematics and range of motion. Med Sci Sports Exerc 2014;46:351-7.

109 Chalmers PN, Wimmer MA, Verma NN, et al. The relationship between Pitching mechanics and injury: a review of current concepts. Sports Health 2017;9:216-21.

110 Laudner K, Lynall R, Williams JG, et al. Thoracolumbar range of motion in baseball pitchers and position players. Int J Sports Phys Ther 2013;8:777-83.

111 Sakata J, Nakamura E, Suzuki T, et al. Efficacy of a prevention program for medial elbow injuries in youth baseball players. $A m \mathrm{~J}$ Sports Med 2018;46:460-9.

112 Sekiguchi T, Hagiwara $\mathrm{Y}, \mathrm{Momma} \mathrm{H}$, et al. Coexistence of trunk or lower extremity pain with elbow and/or shoulder pain among young overhead athletes: a cross-sectional study. Tohoku J Exp Med 2017;243:173-8.

113 Song AY, Jo HJ, Sung PS, et al. Three-Dimensional kinematic analysis of pelvic and lower extremity differences during trunk rotation in subjects with and without chronic low back pain. Physiotherapy 2012;98:160-6.

114 Sung PS. A kinematic analysis for shoulder and pelvis coordination during axial trunk rotation in subjects with and without recurrent low back pain. Gait Posture 2014;40:493-8.

115 Taniguchi M, Tateuchi H, Ibuki S, et al. Relative mobility of the pelvis and spine during trunk axial rotation in chronic low back pain patients: a case-control study. PLoS One 2017;12:e0186369.

116 Wagner $\mathrm{H}$, Pfusterschmied J, Tilp M, et al. Upper-body kinematics in team-handball throw, tennis serve, and volleyball spike. Scand $J$ Med Sci Sports 2014;24:345-54. 